\title{
Association of Notch and Hedgehog Pathway Activation With Prognosis in Early-stage Colorectal Cancer
}

\author{
GRIGORIOS RALLIS ${ }^{1}$, TRIANTAFYLLIA KOLETSA ${ }^{2}$, ZENIA SARIDAKI ${ }^{3}$, KYRIAKI MANOUSOU $^{4}$, \\ GEORGIA-ANGELIKI KOLIOU ${ }^{4}$, IOANNIS KOSTOPOULOS ${ }^{2}$, VASSILIKI KOTOULA ${ }^{2,5}$, \\ THOMAS MAKATSORIS ${ }^{6}$, HELEN P. KOUREA ${ }^{7}$, GEORGIA RAPTOU ${ }^{2}$, SOFIA CHRISAFI $^{3}$, \\ EPAMINONTAS SAMANTAS ${ }^{8}$, KLEO PAPAPARASKEVA $^{9}$, ELISSAVET PAZARLI ${ }^{10}$, PAVLOS PAPAKOSTAS $^{11}$, \\ GEORGIA KAFIRI ${ }^{12}$, DAVIDE MAURI ${ }^{13}$, ALEXANDRA PAPOUDOU-BAI ${ }^{14}$, CHRISTOS CHRISTODOULOU $^{15}$, \\ KALLIOPI PETRAKI ${ }^{16}$, NIKOLAOS DOMBROS ${ }^{17}$, DIMITRIOS PECTASIDES ${ }^{18}$ and GEORGE FOUNTZILAS ${ }^{5,17}$ \\ ${ }^{1}$ Department of Medical Oncology, School of Health Sciences, Faculty of Medicine, \\ Papageorgiou Hospital, Aristotle University of Thessaloniki, Thessaloniki, Greece; \\ ${ }^{2}$ Department of Pathology, School of Health Sciences, Faculty of Medicine, \\ Aristotle University of Thessaloniki, Thessaloniki, Greece; \\ ${ }^{3}$ Asklepios Oncology Department, Heraklion, Greece; \\ ${ }^{4}$ Section of Biostatistics, Hellenic Cooperative Oncology Group, Data Office, Athens, Greece; \\ ${ }^{5}$ Laboratory of Molecular Oncology, Hellenic Foundation for Cancer \\ Research/Aristotle University of Thessaloniki, Thessaloniki, Greece; \\ ${ }^{6}$ Division of Oncology, Department of Medicine, University Hospital, University of Patras Medical School, Patras, Greece; \\ ${ }^{7}$ Department of Pathology, University Hospital of Patras, Patras, Greece; \\ ${ }^{8}$ Third Department of Medical Oncology, Agii Anargiri Cancer Hospital, Athens, Greece; \\ ${ }^{9}$ Department of Pathology, General Hospital Konstantopouleio Agia Olga, Athens, Greece; \\ ${ }^{10}$ Department of Pathology, School of Health Sciences, Faculty of Medicine Thessaloniki, Papageorgiou Hospital, \\ Aristotle University of Thessaloniki, Thessaloniki, Greece; \\ ${ }^{11}$ Oncology Unit, Hippokration Hospital, Athens, Greece; \\ ${ }^{12}$ Department of Pathology, Hippokration Hospital, Athens, Greece; \\ ${ }^{13}$ Department of Medical Oncology, Ioannina University Hospital, Ioannina, Greece; \\ ${ }^{14}$ Department of Pathology, Ioannina University Hospital, Ioannina, Greece; \\ ${ }^{15}$ Second Department of Medical Oncology, Metropolitan Hospital, Piraeus, Greece; \\ ${ }^{16}$ Pathology Department, Metropolitan Hospital, Piraeus, Greece; \\ ${ }^{17}$ Aristotle University of Thessaloniki, Thessaloniki, Greece; \\ ${ }^{18}$ Oncology Section, Second Department of Internal Medicine, Hippokration Hospital, Athens, Greece
}

\begin{abstract}
Background/Aim: Early-stage colorectal cancer $(C R C)$ carries a wide range of survival probabilities. Novel biomarkers in this setting are eagerly awaited. Cancer stem cells (CSCs) are considered one of the reasons for treatment failure.
\end{abstract}

This article is freely accessible online.

Correspondence to: George Fountzilas, MD, Laboratory of Molecular Oncology, Hellenic Foundation for Cancer Research/ Aristotle University of Thessaloniki, Thessaloniki, Greece. Tel: +30 2310683136,e-mail: fountzil@auth.gr

Key Words: Notch, Hedgehog, colorectal cancer, Shh, Smo, Patched-1, Gli-1, Jagged-1, Notch-2, Notch-3.
This study sought to determine whether activation of pathways governing the function of CSC's could correlate with treatment outcomes. Materials and Methods: Tumor specimens from 325 patients were analyzed with immunohistochemistry (IHC) for Hedgehog and Notch pathway activation and results were correlated with prognosis. Results: Positive Notch3 protein expression was an unfavorable prognostic factor for disease-free survival (DFS) and overall survival (OS) $(H R=2.43, p=0.024$ and $H R=2.56, p=0.028$, respectively). Activation of the Shh pathway showed univariately longer DFS (HR=0.49, $p=0.032)$. Possible crosstalk between the two pathways was indicated. No further associations between pathway activation and outcome were evident. Conclusion: Apart from Notch 3, activation of the pathways, as indicated by IHC expression of their components, did not result in differences in terms of DFS or OS. 
Colorectal cancer (CRC) is the second leading cause of cancer-related deaths worldwide, with an estimate of 881,000 deaths occurring in 2018 (1). Despite major advances in early diagnosis, surgical treatment and chemotherapy agents, still, a significant proportion of early-stage cases will develop metastases and ultimately succumb from their disease. One of the reasons for this unfortunate evolution is the presence of cancer stem cells (CSCs), which, among other properties, seem to be resistant to current treatments. Fundamental to the discovery of new treatments targeting CSCs is our full and in depth understanding of the biology behind them (2).

Among the molecular pathways governing the function of CSCs are Hedgehog and Notch. The Hedgehog pathway, first described in 1980 (3), plays an important role during embryogenesis and the development of several organs and tissues, among which the gastrointestinal tract. Deregulation of this pathway is associated with developmental deficits in embryos and cancer development in adult patients. Its role is well established in cases of holoprosencephaly, Gorlin syndrome, basal cell carcinomas and medulloblastomas (4). Mutations or overexpression of the pathway components can result in cancer development (5-8). The Hedgehog family consists of three proteins, sonic (Shh), indian (Ihh) and desert (Dhh), which are the ligands of 12-pass transmembrane protein receptors known as Patched. In the absence of ligand interaction, patched receptors keep the 7-pass transmembrane protein smoothened (Smo) inactive. Upon ligand binding, Smo activates the downstream glioma-associated oncogene homologue isoforms (Gli-1,-2,-3) in the cytoplasm, which then translocate to the nucleus, inducing the expression or downregulation of their target genes (mainly regulatory of the cell cycle or proapoptotic genes) (9). Hedgehog, besides other functions, has been found to be involved in tumorigenic development and cancer metastases both in vitro and in vivo (10). It also seems to play an important role in stem cell survival and self-renewal. Unfortunately, the results are not consistent and findings from several studies are contradictory (11-15).

The Notch Pathway genes were first described in 1917 upon an observation of a genetic anomaly causing the formation of notches in the wings of Drosophila melanogaster (16). Subsequent studies revealed that this pathway plays a crucial role in pattern formation during embryonic development, through specific cell to cell interactions that determine the fate of each cell and inducing the formation of different cells (17). The pathway, in brief, consists of five ligands [Jagged-1, Jagged-2, Delta-like-1 (Dll-1), Delta-like-3 (Dll-3) and Delta-like-4 (Dll-4)], and four receptors (Notch1, Notch2, Notch3 and Notch4) (18). Deregulation of the pathway results in developmental deficits in humans, like the Allagile syndrome (19), cerebral autosomal dominant arteriopathy with subcortical infarcts and leukoencephalopathy (CADASIL) (20), Hajdu-Cheney
Table I. Selected patient and tumor characteristics.

\begin{tabular}{|c|c|}
\hline & $\mathrm{N}(\%)$ \\
\hline \multicolumn{2}{|l|}{ Age } \\
\hline $\mathrm{N}$ & 325 \\
\hline Median & 64.5 \\
\hline Mean (std) & $62.6(10.3)$ \\
\hline Range & $23.7-81.5$ \\
\hline \multicolumn{2}{|l|}{ BMI } \\
\hline $\mathrm{N}$ & 295 \\
\hline Median & 26.7 \\
\hline Mean (std) & $26.8(3.5)$ \\
\hline Range & $17.3-35.0$ \\
\hline \multicolumn{2}{|l|}{ Gender } \\
\hline Woman & $145(44.6 \%)$ \\
\hline Man & $180(55.4 \%)$ \\
\hline \multicolumn{2}{|l|}{ PS (ECOG) } \\
\hline 0 & $297(91.4 \%)$ \\
\hline $1-2$ & $23(7.1 \%)$ \\
\hline Unknown & $5(1.5 \%)$ \\
\hline \multicolumn{2}{|l|}{ Anemia $(\mathrm{Hb}<12 \mathrm{~g} / \mathrm{dL})$} \\
\hline Yes & $68(20.9 \%)$ \\
\hline No & $249(76.6 \%)$ \\
\hline Unknown & $8(2.5 \%)$ \\
\hline \multicolumn{2}{|l|}{ TNM stage } \\
\hline I & $5(1.5 \%)$ \\
\hline II & $112(34.5 \%)$ \\
\hline III & $202(62.2 \%)$ \\
\hline Unknown & $6(1.8 \%)$ \\
\hline \multicolumn{2}{|l|}{ Histological grade } \\
\hline G1 (Well differentiated) & $17(5.2 \%)$ \\
\hline G2 (Moderately differentiated) & $235(72.3 \%)$ \\
\hline G3 (Poorly differentiated) & $64(19.7 \%)$ \\
\hline Unknown & $9(2.8 \%)$ \\
\hline \multicolumn{2}{|l|}{ Obstruction } \\
\hline Yes & $44(13.5 \%)$ \\
\hline No & $280(86.2 \%)$ \\
\hline Unknown & $1(0.3 \%)$ \\
\hline \multicolumn{2}{|l|}{ Perforation } \\
\hline Yes & $28(8.6 \%)$ \\
\hline No & $296(91.1 \%)$ \\
\hline Unknown & $1(0.3 \%)$ \\
\hline \multicolumn{2}{|l|}{ Primary site } \\
\hline Right colon & $98(30.2 \%)$ \\
\hline Left colon & $137(42.2 \%)$ \\
\hline Rectum & $87(26.8 \%)$ \\
\hline Unknown & $3(0.9 \%)$ \\
\hline
\end{tabular}

Std: Standard deviation; BMI: body mass index; PS: performance status; $\mathrm{Hb}$ : hemoglobin.

syndrome (21) and spondylocostal dysostosis (22), but also in neoplasia, like T-ALL (23) and diffuse large B-cell lymphoma (24).

Activation of the pathway starts upon the interaction of the ligands with the receptors. This leads to a proteolytic cleavage of the extracellular part of the receptor followed by a second cleavage in the intracellular part that releases the Notch Intracellular Domain (NICD), which then enters the 
A total of 441 colorectal cancer patients

were randomized in a prospective phase III trial.

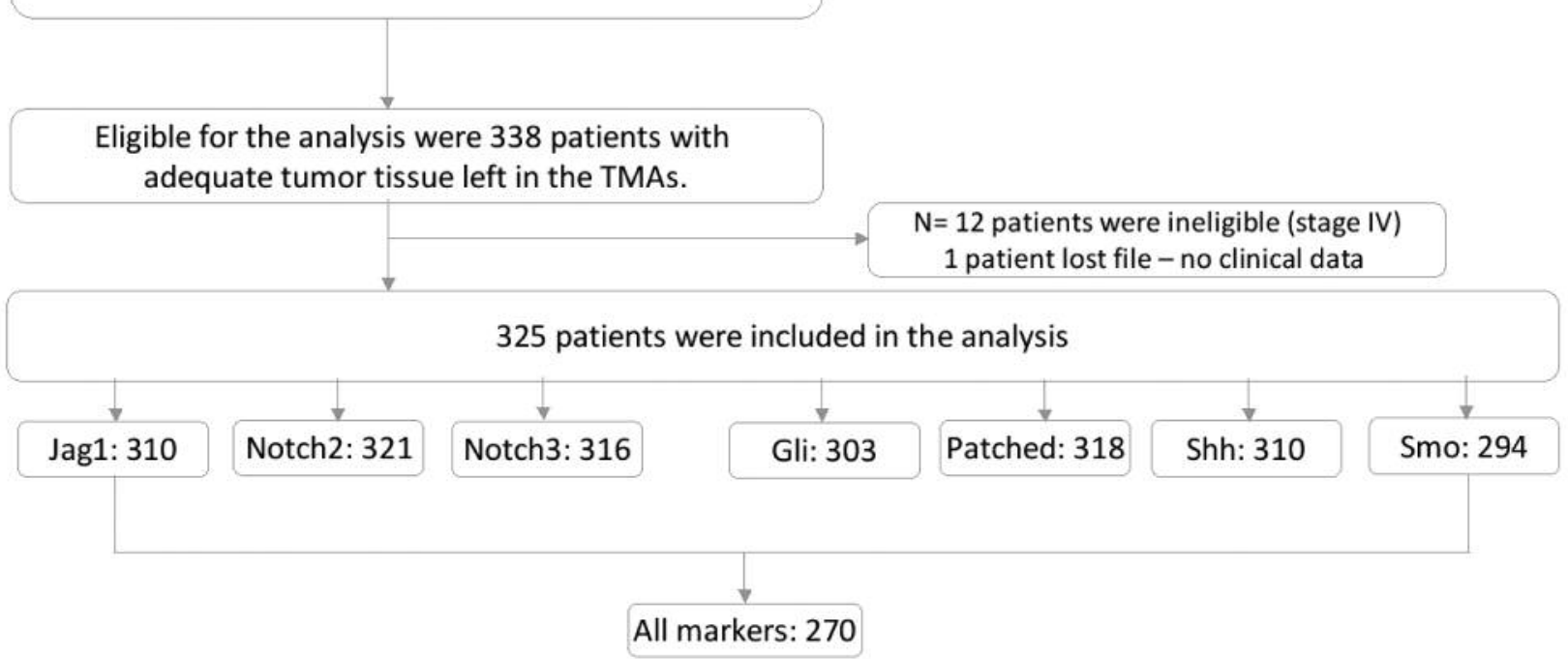

Figure 1. REMARK diagram.

nucleus and forms a transcriptional activation complex that promotes the expression of a number of genes, like Myc, CyclinD, hes1 etc. 1 (25-28). Notch can act both as a major oncogene, associated with tumor progression and metastasis, as well as a tumor suppressor (10). It has been also shown that Notch pathway activation contributes to the development and survival of CSCs $(29,30)$. Especially in colon cancer, an interplay between Notch and Wnt has been documented and it seems that Notch's activation is imperative for the adenoma-carcinoma progression of APC mutant patients (31).

The role of Hedgehog and Notch pathways in solid tumors, among which in $\mathrm{CRC}$, has been studied and reviewed quite extensively $(32,33)$. These are master developmental pathways, commonly activated in many tumors in which they not only play a crucial role in tumor initiation, but also in primary and metastatic tumor development and cancer stem cell regulation (10).

This study sought to correlate the expression of Notch2, Notch3, Jag1, Shh, Smo, Patched-1 and Gli1 with various clinico-pathological parameters and patients' outcome with the intention to identify meaningful associations.

\section{Materials and Methods}

Clinical study. A total of 325 colorectal cancer patients treated with adjuvant chemotherapy within a randomized trial setting (34) were included in the present study (Figure 1). The clinical protocol was approved by the Institutional Review Boards (IRBs) in participating institutions and by the National Organization for Medicines
(53386/14-10-05). The trial was registered in the Australian New Zealand Clinical Trials Registry and allocated the following Registration Number: ANZCTR 12610000509066. The present translational project was approved by the Bioethics Committee of the Aristotle University of Thessaloniki School of Health Sciences, Faculty of Medicine (1/8-11-2012). Written informed consent for participation in the trial was obtained from all the patients and optionally a separate informed consent was obtained for providing biological material for research purposes.

Selected patient and tumor characteristics at baseline are presented in Table I. More than half of the patients were men $(55.4 \%)$ and the median age at diagnosis was 64.5 years. The majority of the tumors were of $\mathrm{G} 2$ histological grade $(\mathrm{N}=235$, $72.3 \%)$ and of stage III $(\mathrm{N}=202,62.2 \%)$. Regarding the primary site, 137 tumors were located in the left colon $(42.2 \%), 98$ in the right colon $(30.2 \%)$ and 87 in the rectum $(26.8 \%)$. Formalin-fixed paraffin-embedded (FFPE) tumor tissues were prospectively collected and retrospectively analyzed for the expression of important biomarkers and the identification of mutations in the KRAS and BRAF genes.

KRAS/BRAF tumor genotyping. Screening of tumor DNA for KRAS mutations (coding exons 1, 2 and 3, CCDS 8702.1) and BRAF V600E mutation (coding exon 15, CCDS 5863.1) was performed with ddsequencing of PCR products, amplified with appropriate M13coupled nested primers, as previously described in detail $(35,36)$.

Immunohistochemical (IHC) evaluation and scoring system. For Notch2, Notch3 and Jag1 staining intensity and percentage of positive cells were evaluated by an experienced pathologist (TK). Regarding the cutoffs, staining intensity was graded as $1+, 2+$ and $3+$, while the percentage of positive cells was scored into four categories $(0$ for $0 \%, 1$ for $1-33 \%, 2$ for $>33-66 \%$ and 3 for $>66$ - 

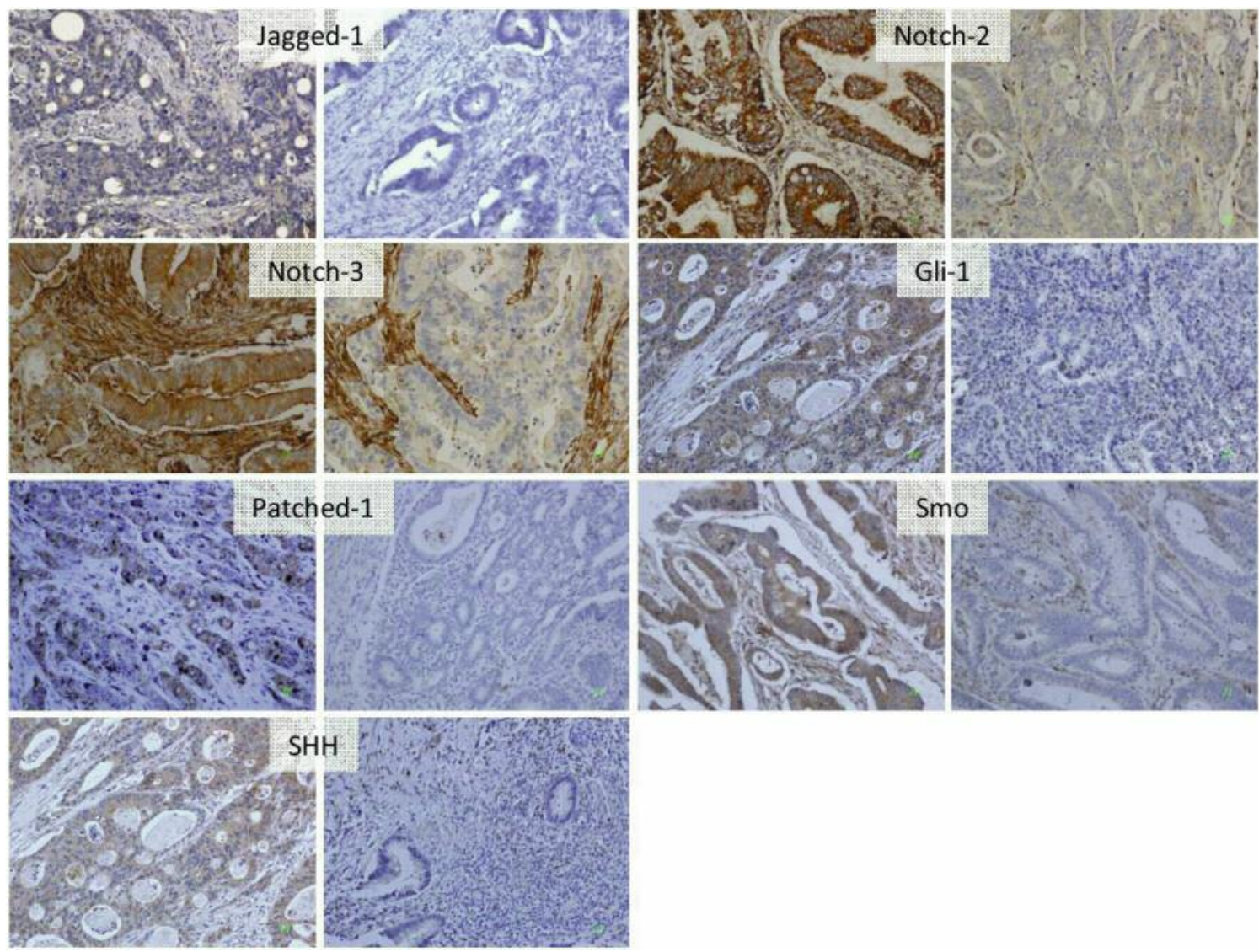

Figure 2. Representative staining images of Notch and Hedgehog pathway markers in colorectal carcinomas. All magnifications $\times 400$. Smo: Smoothened; SHH: Sonic Hedgehog. For each marker: left microphotograph, positive; right microphotograph, negative.

$100 \%)$. The product of the intensity and percentage categories (range $=0-9$ ) was used as the final score and classified as negative (0-4) and positive (5-9). Similarly, for Gli, Patch, Shh and Smo intensity and positivity rates were evaluated. Staining intensity was scored as $1+, 2+$ and $3+$, while the percentage of positive cells was graded as 0 for $<5 \%, 1$ for $5-25 \%, 2$ for $>26-50 \%, 3$ for $>51-75 \%$ and 4 for $>75 \%$. The product of the intensity and percentage categories (range $=0-12$ ) was used as the final score and classified as negative (0-4) and positive (5-12). Representative staining images of Notch and Hedgehog pathway markers are presented in Figure 2.

Tumors were classified, according to IHC positivity for MLH1, PMS2, MSH2 and MSH6, in MMR proficient (pMMR) if all proteins were expressed and MMR deficient (dMMR) in case of null expression of at least one protein.

Statistical analysis. Continuous variables are presented as medians with the corresponding range and categorical variables as frequencies with percentages. The Chi-square or Fisher's exact (where appropriate) test was used for group comparisons of categorical data.

Overall survival (OS) was defined as the time (in months) from the date of colorectal cancer diagnosis to the date of death or last contact, while disease-free survival (DFS) was defined as the time (in months) from the date of diagnosis to the first documented progression, death without prior documented progression or last contact, whichever occurred first. Surviving patients (for OS and DFS) and patients without progression (for DFS) were censored at the date of last contact. Survival distributions were estimated using the Kaplan-Meier method and compared across groups with the log-rank test. The associations between the factors of interest (see below) and progression/mortality rates were evaluated with hazard ratios estimated with univariate and multivariate Cox proportional hazard regression models.

The following parameters were studied in relation to DFS/OS: 1) clinicopathological: age, body mass index (BMI), gender (man, woman), ECOG performance status (0, 1-2), TNM stage (I-II, III), histological grade $(\mathrm{G} 1, \mathrm{G} 2, \mathrm{G} 3)$, obstruction (yes, no), perforation (yes, no), primary site (left colon, right colon, rectum); 2) IHC markers considered as 2-level categorical variables (negative $v s$. positive) using the cut-offs previously described in the "IHC evaluation and scoring system" section: Jag1, Notch2, Notch3, Gli, Patched, Smo, Shh; MMR status (deficient, proficient); 3) mutational markers considered as 2-level categorical variables (mutant, wild-type): BRAF and KRAS. In addition, combined variables were examined with the following categories: Jag1-Notch pathway: (i) Jag1-positive or Noth3-positive and Notch2-positive, indicating the activated state of the pathway; (ii) Notch2-positive only; (iii) other. Shh-pathway: (i) (Gli-positive and Shh-positive) or Smo-positive or Patched-positive, indicating the activated state of the pathway; (ii) other. 

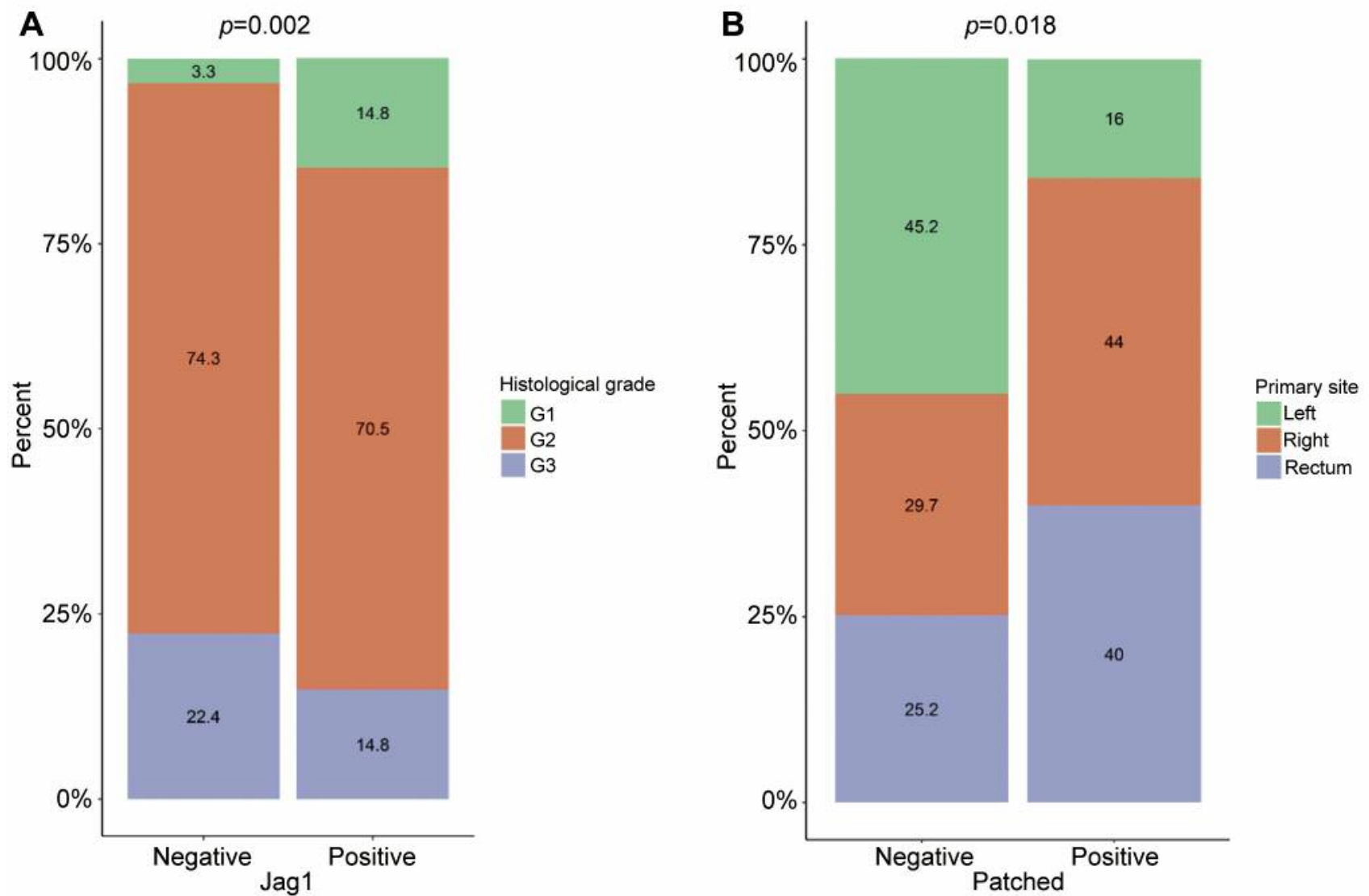

Figure 3. Bar plots showing the association of Jag1 protein expression with histological grade (A); Patched protein expression with primary site (B).

In the multivariate analyses, each of the markers of interest that was found to be significant or revealed a trend towards significance in the univariate analyses $(p<0.10)$ was adjusted for the significant clinicopathological parameters identified by univariate analyses with respect to DFS and OS.

All analyses were performed in the entire cohort of patients. No adjustment for multiple comparisons was performed based on the exploratory nature of the study. Analyses were performed using the SAS (SAS for Windows, version 9.3, SAS Institute Inc., Cary, NC) and R statistical software (37). Statistical significance was set at 2sided $p=0.050$.

\section{Results}

Among 310 tumors informative for Jag1, 321 informative for Notch2 and 316 informative for Notch3, 63 (20.3\%), $241(75.1 \%)$ and $11(3.5 \%)$ were positive, respectively. Similarly, among 303 tumors informative for Gli, 318 informative for Patched, 310 informative for Shh and 294 informative of Smo, 139 tumors (45.9\%), 25 (7.9\%), 292 $(94.2 \%)$ and $15(5.1 \%)$ were positive, respectively. In total, 59 patients had the Jag-Notch pathway activated, while more than half of the patients with informative tumors (149 patients) had the Shh pathway activated. Regarding MMR status, among 288 tumors informative for all MMR proteins, $254(88.2 \%)$ were pMMR. In addition, among 312 NGSinformative tumors, 107 had KRAS mutations and 15 carried $B R A F$ mutations.

Jag1 was significantly associated with Gli (chi-square, $p=0.018)$, Notch2 $(p=0.024)$ and Notch3 ( $p=0.017)$. Jag1positive tumors, compared to Jag1-negative, were more frequently Gli-positive ( $59.3 \%$ vs. $42.1 \%)$, Notch2-positive ( $87.1 \%$ vs. $73.5 \%)$ and Notch3-positive (8.1\% vs. 2\%). Additionally, Shh-positive tumors were more frequently Glipositive compared to Shh-negative tumors (47\% vs. $17.6 \%$, $p=0.018$ ), while Smo-positive tumors were more frequently Patched-positive compared to Smo-negative tumors $(26.7 \%$ vs. $6.1 \%, p=0.003)$. No significant association was observed between any of the IHC markers and $B R A F / K R A S$ mutational status.

Jag1 IHC expression was significantly associated with histological grade $(p=0.002)$. Jag1-positive tumors were more frequently of G1 histological grade compared to Jag1negative tumors (14.8\% vs. 3.3\%, Figure 3A). Additionally, Patched IHC expression was associated with primary site $(p=0.018)$. Patched-positive tumors, compared to Patched- 

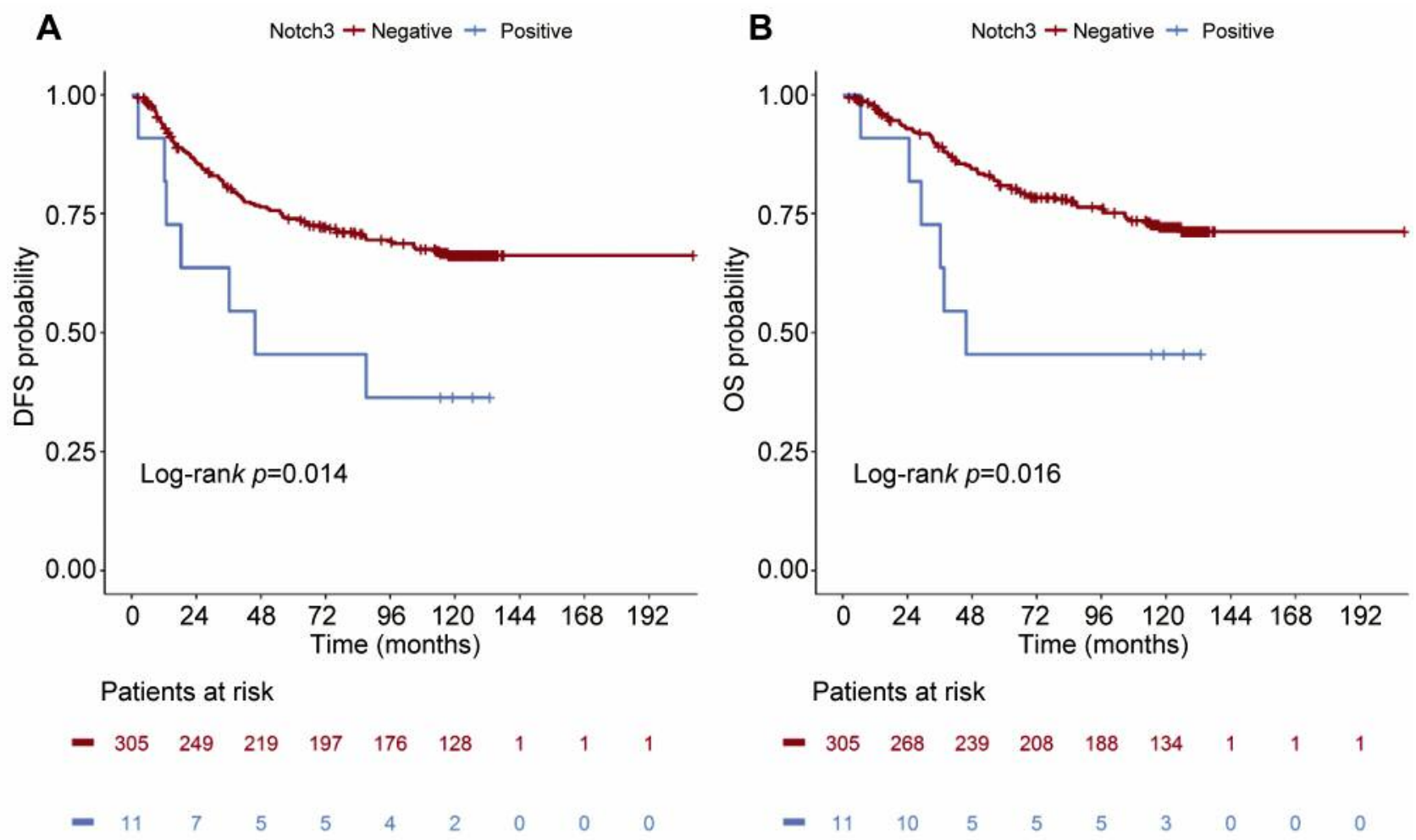

Figure 4. Kaplan-Meier curves with respect to DFS (A) and OS (B) based on Notch3 protein expression.

negative, were more frequently located in the right colon (44.0\% vs. $29.7 \%)$ and less frequently located in the left colon (16.0\% vs. $45.2 \%)$ (Figure 3B). No other significant associations were observed. No significant associations were observed between selected clinicopathological parameters and Jag1-Notch or Shh pathway.

At a median follow-up of 122.6 months $(95 \% \mathrm{CI}=120.9$ 124.4), 87 patients had died $(26.8 \%)$ and 106 had progressed $(32.6 \%)$. The median OS and DFS had not been reached yet at the time of the analysis. Regarding the effect of the study markers on patients' outcome, only positive Notch3 protein expression had a significant, unfavorable effect on both DFS and OS (Figure 4). Notch3-positive patients presented with shorter DFS and OS compared to those with Notch3- negative tumors (DFS HR=2.53, 95\%CI $=1.17-5.45$, Wald's $p=0.018 ; \quad$ OS $\mathrm{HR}=2.67$, $95 \% \mathrm{CI}=1.16-6.13, p=0.021)$. Upon adjustment for age and stage (parameters that showed statistical significance in the univariate analyses for DFS and OS), positive Notch3 expression retained its unfavorable prognostic significance for DFS and OS (Table II). However, the power of these results is limited by the small number of patients with Notch3-positive tumors and should, therefore, be interpreted with care until further validated in larger cohorts. Similarly, when examining the effect of Jag1-Notch pathway and Shh- pathway activation on DFS and OS no significant associations were observed (DFS log-rank $p=0.91$ and $p=0.14$ and OS log-rank $p=0.86$ and $p=0.21$, respectively). Of note, patients with activated Shh pathway seemed to fair better in terms of DFS after the first two years. The hazard rate functions of each category of the Shh pathway parameter (activated, other) for DFS were assessed. Patients in both groups seemed to have the same hazard ratio for the first 20 months of follow-up (i.e. activated $v s$. other, HR is approximately 1). However, between 20 and 70 months, patients with activated Shh pathway seemed to have a lower hazard ratio compared to patients without an activated pathway (i.e., activated $v s$. other, HR $<1$ ). In comparison, in the period between 70 and 100 months the hazard ratio of the activated group increased while, simultaneously, the hazard ratio in the non-activated group decreased and the relationship was reversed (i.e., activated $v s$. other, HR >1). Therefore, the effect of Shh pathway activation was further examined, excluding patients with a DFS lower than 20 and greater than 70 months. A significant association was observed between Shh pathway activation and reduced risk for progression $(\mathrm{HR}=0.49,95 \% \mathrm{CI}=0.26-0.94, p=0.032)$, which however was not retained in the multivariate analysis adjusting for age and stage $(\mathrm{HR}=0.54,95 \% \mathrm{CI}=0.26-1.10$, $p=0.088$, Table II). 
Table II. Hazard ratios and 95\%CIs estimated by univariate and multivariate Cox regression models with respect to DFS and OS.

\begin{tabular}{|c|c|c|c|c|c|c|}
\hline & \multicolumn{3}{|c|}{ Univariate } & \multicolumn{3}{|c|}{ Multivariate $^{1}$} \\
\hline & Event/Total & Hazard Ratio (95\%CI) & $p$-Value & Event/Total & Adjusted Hazard Ratio (95\%CI) & Adjusted $p$-Value \\
\hline \multicolumn{7}{|l|}{ DFS } \\
\hline \multicolumn{7}{|l|}{ Notch3 } \\
\hline Negative & $96 / 305$ & Reference & -- & $94 / 299$ & Reference & -- \\
\hline Positive & $7 / 11$ & $2.53(1.17-5.45)$ & 0.018 & $7 / 11$ & $2.43(1.13-5.27)$ & 0.024 \\
\hline \multicolumn{7}{|c|}{ Shh pathway* } \\
\hline Activated & $15 / 22$ & $0.49(0.26-0.94)$ & 0.032 & $15 / 22$ & $0.54(0.26-1.10)$ & 0.088 \\
\hline Other & $28 / 31$ & Reference & -- & $26 / 29$ & Reference & -- \\
\hline \multicolumn{7}{|l|}{ OS } \\
\hline \multicolumn{7}{|l|}{ Notch3 } \\
\hline Negative & $78 / 305$ & Reference & -- & $76 / 299$ & Reference & -- \\
\hline Positive & $6 / 11$ & $2.67(1.16-6.13)$ & 0.021 & $6 / 11$ & $2.56(1.11-5.92)$ & 0.028 \\
\hline
\end{tabular}

${ }^{1}$ Adjusted for age and stage. * for the period of 20 months $\leq$ DFS $\leq 70$ months. CI: Confidence interval.

\section{Discussion}

In this observational study, $325 \mathrm{CRC}$ patients and their respective CRC tumor specimens were analyzed retrospectively for important and relevant to CRC biomarkers (KRAS, BRAF, MMR status), as well as, for the evaluation of two major developmental pathways, Notch and Hedgehog, and the results were correlated with clinicopathological parameters and outcome.

The strongest point of our study regards Notch3. Patients whose tumors expressed high levels of Notch3 were shown to have worse outcomes, meaning, approximately 2.5 times reduced DFS and OS as this is evident from the respective HRs. These findings agree with current evidence in the international literature, where an association between high levels of Notch3 and a more aggressive malignant cell phenotype has been described (38). Nevertheless, due to the small number of patients in the Notch3-positive group $(\mathrm{N}=11)$, our results should be interpreted with caution. Furthermore, our analysis showed a statistically significant association between Notch3 positivity and the existence of BRAF mutation in CRC tumors, but again, due to the very limited numbers, this observation should be interpreted cautiously.

In our study $75.1 \%$ of the patients were IHC Notch2 positive. Indeed, high Notch2 expression has been observed in the majority of GI malignant cells in various publications (39-41). Unfortunately, this observation was not correlated with outcome in our series, as it was elsewhere $(42,43)$.

The role of Jagged-1 in CRC still remains elusive. Overexpression has been correlated with bad prognosis, especially when combined with high levels of Notch2, and with increased probability for relapse and lymph node metastasis (44). Furthermore, Jagged-1 expression intensity has been correlated with higher grade, higher TNM stage, depth of infiltration and lymph node metastasis (45), something that was not replicated in our analysis, where more patients were included and Jagged-1 expression was statistically significantly associated with a lower grade at diagnosis.

In several studies, Gli1 expression level in CRC tissues varies from $30 \%$ to $79 \%$, with staining being either cytoplasmic or nuclear (46-51). In our study, $45,87 \%$ of the tumors stained positive for Gli-1. Expression of Gli-1 protein in colon cancer tissues seems to play a key role in the occurrence and development of colon cancer, while high Gli1 expression may promote postoperative liver metastasis development (52). In our study, no significant associations between Gli-1 and prognosis were found.

Crosstalk of Notch pathway with other embryonic pathways, such as WNT, has been implied in the literature $(39,53)$, but little is known about any associations with the Hedgehog pathway. In our study, statistically significant associations were observed between Jagged-1 expression and Gli-1 expression. Since Gli-1 is the primary effector molecule of the Hedgehog pathway activation, this association may indicate a possible crosstalk between the two pathways, a notion that needs further exploration.

Patched-1 overexpression has been correlated with moderately differentiated tumors (47) and nodal status (50), as well as, with worse DFS and OS in patients with earlystage cancer that underwent curative treatment $(47,50)$. Contradictory results were reported in a small study of 19 patients, where low levels of Patched-1 mRNA expression were associated with a higher risk of metastasis (54). In our study, an association between Patched-1 expression and location of the primary tumor was observed, with the right sided tumors showing high expression, whereas the left sided tumors showed low expression. No association of Patched-1 expression with stage, DFS or OS was detected. 
Smo, like Patched-1, is one of the two transmembrane proteins of the Hedgehog pathway that along with the downstream glioma-associated transcription factors are responsible for the activity of the pathway. High levels of this molecule have been described in colorectal cancer cells. Higher Smo expression has been correlated with an increased probability of lymph node metastasis and higher $\mathrm{T}$ stage (48). Apart from the expected correlation of Smo-positive, with Gli- and Patched-1-positive tumors, no other significant associations of Smo were observed in our series.

It has been reported that epithelial malignancies of the adult gut are associated with abnormal SHH/SHH expression $(11,55,56)$. In concordance with this observation, in our study, $94.2 \%$ of the CRC tumors overexpressed Shh. Furthermore, in a retrospective analysis it was shown that Shh overexpression is associated with poorer DFS and OS in patients with non-metastatic colorectal cancer that underwent curative surgery (50). In our series, patients with an activated Shh pathway seemed to fair better in terms of DFS after the first two years, during which the majority of relapses have occurred. In contrast, in the follow-up period of 70 to 100 months, the HR of the Shh activated group was increased. When excluding from the analysis patients with a DFS lower than 20 months (poor prognosis patients) and greater than 70 months (good prognosis patients) Shh activation characterized the patients that would experience a reduced risk for relapse; this is an observation that could justify further exploration.

\section{Conclusion}

Although the Notch and Hedgehog pathways have been shown in several studies to play a role in CRC development and progression, data are still contradictory and unclear (57). In our study, activation of the two examined pathways, as this is indicated by IHC overexpression of their components, did not result in significant associations in terms of outcome in early-stage CRC patients, with the exception of Notch3. Due to the retrospective nature of our analysis and the limited number of Notch3-positive tumors, our data are not enough to promote Notch3 to a putative biomarker indicative of early progression. Nevertheless, it is possible that potential biomarkers may be "hiding" alongside these two pathways, and further research is warranted in order to depict their exact role in the metastatic evolution in CRC patients.

\section{Authors' Contributions}

Study Conception: GR, TK, ND, GF; Study Design: GR, TK, KM, GAK, IK, VK, ND, GF; Acquisition of data: GR, TM, HPK, GR, ES, KP, EP, PP, GK, DM, APB, CC, KP, DP, GF; Analysis and interpretation of data: GR, TK, ZS, KM, GAK, IK, VK, SC, ND, GF; Drafted and revised the manuscript: GR, TK, ZS, KM, GAK, IK, VK, SC, ND, GF; All Authors have revised and approved the final version.

\section{Acknowledgements}

The Authors are indebted to all patients and their families for the provision of biological material for research purposes. The Authors would also like to thank Emily Daskalaki for excellent technical assistance, Helen Sgouramalli, MSc for block sectioning, Maria Moschoni for coordinating the data management and Stella Dallidou for secretarial assistance.

This study was supported by an internal Hellenic Cooperative Oncology Group (HeCOG) translational research grant (HE TRANS_CRC) and by a Hellenic Society for Medical Oncology (HeSMO) grant. The funders played no role in study design, data collection and analysis, decision to publish, or preparation of the manuscript.

\section{References}

1 Bray F, Ferlay J, Soerjomataram I, Siegel RL, Torre LA and Jemal A: Global cancer statistics 2018: Globocan estimates of incidence and mortality worldwide for 36 cancers in 185 countries. CA Cancer J Clin 68(6): 394-424, 2018. PMID: 30207593. DOI: $10.3322 /$ caac. 21492

2 Annett S and Robson T: Targeting cancer stem cells in the clinic: Current status and perspectives. Pharmacol Ther 187: 13-30, 2018. PMID: 29421575. DOI: 10.1016/j.pharmthera.2018.02.001

3 Nusslein-Volhard C and Wieschaus E: Mutations affecting segment number and polarity in drosophila. Nature 287(5785): 795-801, 1980. PMID: 6776413.

4 Mullor JL, Sanchez P and Ruiz i Altaba A: Pathways and consequences: Hedgehog signaling in human disease. Trends Cell Biol 12(12): 562-569, 2002. PMID: 12495844.

5 McMahon AP, Ingham PW and Tabin CJ: Developmental roles and clinical significance of hedgehog signaling. Curr Top Dev Biol 53: 1-114, 2003. PMID: 12509125.

6 Johnson RL, Rothman AL, Xie J, Goodrich LV, Bare JW, Bonifas JM, Quinn AG, Myers RM, Cox DR, Epstein EH Jr. and Scott MP: Human homolog of patched, a candidate gene for the basal cell nevus syndrome. Science 272(5268): 1668-1671, 1996. PMID: 8658145.

7 Dahmane N, Lee J, Robins P, Heller P and Ruiz i Altaba A: Activation of the transcription factor gli1 and the sonic hedgehog signalling pathway in skin tumours. Nature 389(6653): 876-881, 1997. PMID: 9349822. DOI: $10.1038 / 39918$

8 Taylor MD, Liu L, Raffel C, Hui CC, Mainprize TG, Zhang X, Agatep R, Chiappa S, Gao L, Lowrance A, Hao A, Goldstein AM, Stavrou T, Scherer SW, Dura WT, Wainwright B, Squire JA, Rutka JT and Hogg D: Mutations in sufu predispose to medulloblastoma. Nat Genet 31(3): 306-310, 2002. PMID: 12068298. DOI: $10.1038 / n g 916$

9 Lauth M, Bergstrom A, Shimokawa T and Toftgard R: Inhibition of gli-mediated transcription and tumor cell growth by smallmolecule antagonists. Proc Natl Acad Sci USA 104(20): 84558460, 2007. PMID: 17494766. DOI: 10.1073/pnas.0609699104

10 Nwabo Kamdje AH, Takam Kamga P, Tagne Simo R, Vecchio L, Seke Etet PF, Muller JM, Bassi G, Lukong E, Kumar Goel R, Mbo Amvene $\mathrm{J}$ and Krampera M: Developmental pathways associated with cancer metastasis: Notch, wnt, and hedgehog. Cancer Biol Med 14(2): 109-120, 2017. PMID: 28607802. DOI: 10.20892/j.issn.2095-3941.2016.0032 
11 Alinger B, Kiesslich T, Datz C, Aberger F, Strasser F, Berr F, Dietze O, Kaserer $\mathrm{K}$ and Hauser-Kronberger C: Hedgehog signaling is involved in differentiation of normal colonic tissue rather than in tumor proliferation. Virchows Arch 454(4): 369379, 2009. PMID: 19280222. DOI: 10.1007/s00428-009-0753-7

12 Varnat F, Duquet A, Malerba M, Zbinden M, Mas C, Gervaz P and Ruiz i Altaba A: Human colon cancer epithelial cells harbour active hedgehog-gli signalling that is essential for tumour growth, recurrence, metastasis and stem cell survival and expansion. EMBO Mol Med 1(6-7): 338-351, 2009. PMID: 20049737. DOI: $10.1002 / \mathrm{emmm} .200900039$

13 Varnat F, Siegl-Cachedenier I, Malerba M, Gervaz P and Ruiz i Altaba A: Loss of wnt-tcf addiction and enhancement of hh-gli1 signalling define the metastatic transition of human colon carcinomas. EMBO Mol Med 2(11): 440-457, 2010. PMID: 20941789. DOI: $10.1002 / \mathrm{emmm} .201000098$

14 Chatel G, Ganeff C, Boussif N, Delacroix L, Briquet A, Nolens $\mathrm{G}$ and Winkler R: Hedgehog signaling pathway is inactive in colorectal cancer cell lines. Int J Cancer 121(12): 2622-2627, 2007. PMID: 17683069 . DOI: $10.1002 / \mathrm{ijc} .22998$

15 Taniguchi H, Yamamoto H, Akutsu N, Nosho K, Adachi Y, Imai $\mathrm{K}$ and Shinomura Y: Transcriptional silencing of hedgehoginteracting protein by cpg hypermethylation and chromatic structure in human gastrointestinal cancer. J Pathol 213(2): 131139, 2007. PMID: 17724792. DOI: 10.1002/path.2216

16 Morgan TH: The theory of the gene. American Naturalist 51: 513-544, 1917.

17 Lai EC: Notch signaling: Control of cell communication and cell fate. Development 131(5): 965-973, 2004. PMID: 14973298 DOI: $10.1242 / \mathrm{dev} .01074$

18 Artavanis-Tsakonas S, Rand MD and Lake RJ: Notch signaling: Cell fate control and signal integration in development. Science 284(5415): 770-776, 1999. PMID: 10221902.

19 Li L, Krantz ID, Deng Y, Genin A, Banta AB, Collins CC, Qi M, Trask BJ, Kuo WL, Cochran J, Costa T, Pierpont ME, Rand EB, Piccoli DA, Hood L and Spinner NB: Alagille syndrome is caused by mutations in human jagged1, which encodes a ligand for notch 1. Nat Genet 16(3): 243-251, 1997. PMID: 9207788. DOI: $10.1038 / \mathrm{ng} 0797-243$

20 Joutel A, Corpechot C, Ducros A, Vahedi K, Chabriat H, Mouton $\mathrm{P}$, Alamowitch S, Domenga V, Cecillion M, Marechal E, Maciazek J, Vayssiere C, Cruaud C, Cabanis EA, Ruchoux MM, Weissenbach J, Bach JF, Bousser MG and Tournier-Lasserve E: Notch3 mutations in cadasil, a hereditary adult-onset condition causing stroke and dementia. Nature 383(6602): 707-710, 1996. PMID: 8878478. DOI: $10.1038 / 383707 \mathrm{a} 0$

21 Simpson MA, Irving MD, Asilmaz E, Gray MJ, Dafou D, Elmslie FV, Mansour S, Holder SE, Brain CE, Burton BK, Kim KH, Pauli RM, Aftimos S, Stewart H, Kim CA, HolderEspinasse M, Robertson SP, Drake WM and Trembath RC: Mutations in notch2 cause hajdu-cheney syndrome, a disorder of severe and progressive bone loss. Nat Genet 43(4): 303-305, 2011. PMID: 21378985. DOI: 10.1038/ng.779

22 Bulman MP, Kusumi K, Frayling TM, McKeown C, Garrett C, Lander ES, Krumlauf R, Hattersley AT, Ellard S and Turnpenny PD: Mutations in the human delta homologue, d1l3, cause axial skeletal defects in spondylocostal dysostosis. Nat Genet 24(4): 438-441, 2000. PMID: 10742114. DOI: 10.1038/74307

23 Weng AP, Ferrando AA, Lee W, Morris JPt, Silverman LB, Sanchez-Irizarry C, Blacklow SC, Look AT and Aster JC:
Activating mutations of notch1 in human $\mathrm{t}$ cell acute lymphoblastic leukemia. Science 306(5694): 269-271, 2004. PMID: 15472075. DOI: 10.1126/science. 1102160

24 Lee SY, Kumano K, Nakazaki K, Sanada M, Matsumoto A, Yamamoto G, Nannya Y, Suzuki R, Ota S, Ota Y, Izutsu K, Sakata-Yanagimoto M, Hangaishi A, Yagita H, Fukayama M, Seto M, Kurokawa M, Ogawa S and Chiba S: Gain-of-function mutations and copy number increases of notch 2 in diffuse large b-cell lymphoma. Cancer Sci 100(5): 920-926, 2009. PMID: 19445024.

25 Fehon RG, Kooh PJ, Rebay I, Regan CL, Xu T, Muskavitch MA and Artavanis-Tsakonas S: Molecular interactions between the protein products of the neurogenic loci notch and delta, two EFG-homologous genes in drosophila. Cell 61(3): 523-534, 1990. PMID: 2185893.

26 Mumm JS, Schroeter EH, Saxena MT, Griesemer A, Tian X, Pan DJ, Ray WJ and Kopan R: A ligand-induced extracellular cleavage regulates gamma-secretase-like proteolytic activation of notch1. Mol Cell 5(2): 197-206, 2000. PMID: 10882062.

27 Louvi A and Artavanis-Tsakonas S: Notch signalling in vertebrate neural development. Nat Rev Neurosci 7(2): 93-102, 2006. PMID: 16429119. DOI: 10.1038/nrn1847

28 Nichols JT, Miyamoto A, Olsen SL, D'Souza B, Yao C and Weinmaster G: DSL ligand endocytosis physically dissociates notch1 heterodimers before activating proteolysis can occur. J Cell Biol 176(4): 445-458, 2007. PMID: 17296795. DOI: 10.1083/jcb.200609014

29 Leow CC, Romero MS, Ross S, Polakis P and Gao WQ: Hath1, down-regulated in colon adenocarcinomas, inhibits proliferation and tumorigenesis of colon cancer cells. Cancer Res 64(17): 6050-6057, 2004. PMID: 15342386. DOI: 10.1158/00085472.can-04-0290

30 Sikandar SS, Pate KT, Anderson S, Dizon D, Edwards RA, Waterman ML and Lipkin SM: Notch signaling is required for formation and self-renewal of tumor-initiating cells and for repression of secretory cell differentiation in colon cancer. Cancer Res 70(4): 1469-1478, 2010. PMID: 20145124. DOI: 10.1158/0008-5472.can-09-2557

31 van Es JH, van Gijn ME, Riccio O, van den Born M, Vooijs M, Begthel H, Cozijnsen M, Robine S, Winton DJ, Radtke F and Clevers H: Notch/gamma-secretase inhibition turns proliferative cells in intestinal crypts and adenomas into goblet cells. Nature 435(7044): 959-963, 2005. PMID: 15959515. DOI: 10.1038/ nature 03659

32 Vinson KE, George DC, Fender AW, Bertrand FE and Sigounas G: The notch pathway in colorectal cancer. Int J Cancer 138(8): 1835-1842, 2016. PMID: 26264352. DOI: 10.1002/ijc.29800

33 Papadopoulos V, Tsapakidis K, Riobo Del Galdo NA, Papandreou CN, Del Galdo F, Anthoney A, Sakellaridis N, Dimas K and Kamposioras K: The prognostic significance of the hedgehog signaling pathway in colorectal cancer. Clin Colorectal Cancer 15(2): 116-127, 2016. PMID: 27032873. DOI: 10.1016/ j.clcc.2016.02.010

34 Pectasides D, Karavasilis V, Papaxoinis G, Gourgioti G, Makatsoris T, Raptou G, Vrettou E, Sgouros J, Samantas E, Basdanis G, Papakostas P, Bafaloukos D, Kotoula V, Kalofonos HP, Scopa CD, Pentheroudakis G and Fountzilas G: Randomized phase iii clinical trial comparing the combination of capecitabine and oxaliplatin (CAPOX) with the combination of 5fluorouracil, leucovorin and oxaliplatin (modified FOLFOX6) as 
adjuvant therapy in patients with operated high-risk stage II or stage III colorectal cancer. BMC Cancer 15: 384, 2015. PMID: 25956750. DOI: 10.1186/s12885-015-1406-7.

35 Pentheroudakis G, Raptou G, Kotoula V, Wirtz RM, Vrettou E, Karavasilis V, Gourgioti G, Gakou C, Syrigos KN, Bournakis E, Rallis G, Varthalitis I, Galani E, Lazaridis G, Papaxoinis G, Pectasides D, Aravantinos G, Makatsoris T, Kalogeras KT and Fountzilas G: Immune response gene expression in colorectal cancer carries distinct prognostic implications according to tissue, stage and site: A prospective retrospective translational study in the context of a hellenic cooperative oncology group randomised trial. PLoS One 10(5): e0124612, 2015. PMID: 25970543. DOI: 10.1371/journal.pone.0124612

36 Cohen SA, Wu C, Yu M, Gourgioti G, Wirtz R, Raptou G, Gkakou C, Kotoula V, Pentheroudakis G, Papaxoinis G, Karavasilis V, Pectasides D, Kalogeras KT, Fountzilas G and Grady WM: Evaluation of CPG island methylator phenotype as a biomarker in colorectal cancer treated with adjuvant oxaliplatin. Clin Colorectal Cancer 15(2): 164-169, 2016. PMID: 26702772. DOI: $10.1016 /$ j.clcc.2015.10.005

37 R Core Team: R: A Language and Environment for Statistical Computing Vienna, Austria: Foundation for Statistical Computing. Available from: http://www.R-project.org/

38 Pasto A, Serafin V, Pilotto G, Lago C, Bellio C, Trusolino L, Bertotti A, Hoey T, Plateroti M, Esposito G, Pinazza M, Agostini M, Nitti D, Amadori A and Indraccolo S: Notch3 signaling regulates musashi-1 expression in metastatic colorectal cancer cells. Cancer Res 74(7): 2106-2118, 2014. PMID: 24525742. DOI: $10.1158 / 0008-5472 . c a n-13-2022$

39 Peignon G, Durand A, Cacheux W, Ayrault O, Terris B, LaurentPuig P, Shroyer NF, Van Seuningen I, Honjo T, Perret C and Romagnolo B: Complex interplay between $\beta$-catenin signalling and notch effectors in intestinal tumorigenesis. Gut 60(2): 166176, 2011. PMID: 21205878. DOI: 10.1136/gut.2009.204719

40 Gao J, Long B and Wang Z: Role of notch signaling pathway in pancreatic cancer. Am J Cancer Res 7(2): 173-186, 2017. PMID: 28337369.

41 Yao Y, Ni Y, Zhang J, Wang H and Shao S: The role of notch signaling in gastric carcinoma: Molecular pathogenesis and novel therapeutic targets. Oncotarget 8(32): 53839-53853, 2017. PMID: 28881855. DOI: 10.18632/oncotarget.17809

42 Chen J, Zhang H, Chen Y, Qiao G, Jiang W, Ni P, Liu X and Ma L: Mir-598 inhibits metastasis in colorectal cancer by suppressing jag1/notch2 pathway stimulating emt. Exp Cell Res 352(1): 104112, 2017. PMID: 28161537. DOI: 10.1016/j.yexcr. 2017.01.022

43 Chu D, Zhang Z, Zhou Y, Wang W, Li Y, Zhang H, Dong G, Zhao $\mathrm{Q}$ and Ji G: Notch1 and notch2 have opposite prognostic effects on patients with colorectal cancer. Ann Oncol 22(11): 2440-2447, 2011. PMID: 21378202. DOI: 10.1093/annonc/ mdq776

44 Sugiyama M, Oki E, Nakaji Y, Tsutsumi S, Ono N, Nakanishi R, Sugiyama M, Nakashima Y, Sonoda H, Ohgaki K, Yamashita N, Saeki H, Okano S, Kitao H, Morita M, Oda Y and Maehara Y: High expression of the notch ligand jagged-1 is associated with poor prognosis after surgery for colorectal cancer. Cancer Sci 107(11): 1705-1716, 2016. PMID: 27589478. DOI: 10.1111/ cas.13075

45 Zheng CG, Chen R, Xie JB, Liu CB, Jin Z and Jin C: Immunohistochemical expression of notch1, jagged1, NF-kappab and MMP-9 in colorectal cancer patients and the relationship to clinicopathological parameters. Cancer Biomark 15(6): 889-897, 2015. PMID: 26406415. DOI: $10.3233 / \mathrm{cbm}-150533$
46 Bian YH, Huang SH, Yang L, Ma XL, Xie JW and Zhang HW: Sonic hedgehog-glil pathway in colorectal adenocarcinomas. World J Gastroenterol 13(11): 1659-1665, 2007. PMID: 17461467. DOI: 10.3748/wjg.v13.i11.1659

$47 \mathrm{Hu}$ X, Lai D, Chen W, Zi S, Li J, Du P, Wang Z, Huang S and Long C: Differential expression profiles of the hedgehog signaling pathway between microsatellite-stable and microsatellite-unstable colorectal cancers. Mol Med Rep 4(5): 873-877, 2011. PMID: 21725600. DOI: 10.3892/mmr.2011.529

48 Ding YL, Wang QS, Zhao WM and Xiang L: Expression of smoothened protein in colon cancer and its prognostic value for postoperative liver metastasis. Asian Pac J Cancer Prev 13(8): 4001-4005, 2012. PMID: 23098507.

49 Wang H, Li YY, Wu YY and Nie YQ: Expression and clinical significance of hedgehog signaling pathway related components in colorectal cancer. Asian Pac J Cancer Prev 13(5): 2319-2324, 2012. PMID: 22901214.

$50 \mathrm{Xu} \mathrm{M}, \mathrm{Li}$ X, Liu T, Leng A and Zhang G: Prognostic value of hedgehog signaling pathway in patients with colon cancer. Med Oncol 29(2): 1010-1016, 2012. PMID: 21424326. DOI: 10.1007/ s12032-011-9899-7

51 Hong KD, Lee Y, Kim BH, Lee SI and Moon HY: Expression of GLI1 correlates with expression of lymphangiogenesis proteins, vascular endothelial growth factor $\mathrm{C}$ and vascular endothelial growth factor receptor 3, in colorectal cancer. Am Surg 79(2): 198-204, 2013. PMID: 23336661.

52 Ding YL, Zhou Y, Xiang L, Ji ZP and Luo ZH: Expression of glioma-associated oncogene homolog 1 is associated with invasion and postoperative liver metastasis in colon cancer. Int J Med Sci 9(5): 334-338, 2012. PMID: 22745574. DOI: $10.7150 / \mathrm{ijms} .4553$

53 Fre S, Pallavi SK, Huyghe M, Lae M, Janssen KP, Robine S, Artavanis-Tsakonas S and Louvard D: Notch and wnt signals cooperatively control cell proliferation and tumorigenesis in the intestine. Proc Natl Acad Sci USA 106(15): 6309-6314, 2009. PMID: 19251639. DOI: 10.1073/pnas.0900427106

54 You S, Zhou J, Chen S, Zhou P, Lv J, Han X and Sun Y: Ptch1, a receptor of hedgehog signaling pathway, is correlated with metastatic potential of colorectal cancer. Ups J Med Sci 115(3): 169-175, 2010. PMID: 20230186. DOI: 10.3109/0300973 1003668316

55 Berman DM, Karhadkar SS, Maitra A, Montes De Oca R, Gerstenblith MR, Briggs K, Parker AR, Shimada Y, Eshleman JR, Watkins DN and Beachy PA: Widespread requirement for hedgehog ligand stimulation in growth of digestive tract tumours. Nature 425(6960): 846-851, 2003. PMID: 14520411. DOI: $10.1038 /$ nature 01972

56 Douard R, Moutereau S, Pernet P, Chimingqi M, Allory Y, Manivet P, Conti M, Vaubourdolle M, Cugnenc PH and Loric S: Sonic hedgehog-dependent proliferation in a series of patients with colorectal cancer. Surgery 139(5): 665-670, 2006. PMID: 16701100. DOI: $10.1016 /$ j.surg.2005.10.012

57 Wu C, Zhu X, Liu W, Ruan T and Tao K: Hedgehog signaling pathway in colorectal cancer: Function, mechanism, and therapy. Onco Targets Ther 10: 3249-3259, 2017. PMID: 28721076. DOI: 10.2147/ott.s139639

Received February 14, 2019 Revised March 6, 2019 Accepted March 14, 2019 